\title{
Metaphor, Architectural Design, and Environmental Response
}

Brook Muller, University of Oregon 
"All truly meaningful speech is inherently creative, using established words in ways they have never quite been used before, and thus altering, ever so slightly, the entire webwork of the language." -David Abram ${ }^{1}$

"By 'strung out between wilderness and site,' I mean that we drastically lack viable and significant intermediate positions between these two extremities." - Edward Casey ${ }^{2}$

\begin{abstract}
Value-laden articulations of the task of the architect guide manners of working - the concerns, inspirations and procedures given priority. Architectural practices in turn determine the nature of the physical constructs that result. If architects are contributing to environmental degradation by designing buildings that are inefficient and unhealthy, and a pressing need exists to advance more life enhancing, sustaining practices, then perhaps environmentally concerned architects ought not only work towards the creation of better performing, more resourceful building assemblies, but also to engage in basic reflection as to how design problems are expressed and the environmental receptivity such expressions reveal. By tracing the lineage binding utterance to practice to making, we might come to recognize that even subtle shifts in articulation can alter outcomes dramatically. Through such newfound awareness, we are open and encouraged to reexamine the architect's role, to new descriptions of architecture, and to the possibility of deeper attunement and constructive engagement with our world.
\end{abstract}

In their recent edited anthology on sustainable architectures, Simon Guy and Steven Moore suggest "while we might support and even encourage critical engagement with abstract theory about environmentalism, we are not interested in simply playing language games." 2 Although word play should not be the sole focus of our efforts, in a profession so reliant on effective communication, we should not underestimate the facility of language as constitutive of meaning.3 This paper explores metaphors as one potentially transformative means by which designers come to understand and describe the works they undertake. It examines the role of metaphors as agents of innovation, capable of heightening awareness of attributes often overlooked or undervalued, yet perhaps of critical significance given the particularities of a design problem seeking explication. This paper summarizes research into the process by which architects "respatialize" metaphors, how novel metaphorical insights have affected thought and practice in the past, and in our era of environmental crises how new categories of metaphor are reshaping and expanding our visions. The paper concludes with a consideration of what makes "green" metaphors effective and how awareness of such characteristics provides the impetus for future research in identifying and utilizing new metaphorical schemas in architectural design.

\section{Metaphor, Design Thinking and Design Culture ${ }^{4}$}

"In all aspects of life...we define our reality in terms of metaphors and then proceed to act on the basis of the metaphors. We draw inferences, set goals, make commitments, and execute plans, all on the basis of how we in part structure our experience, consciously and unconsciously, by means of metaphor." -George Lakoff and Mark Johnson. ${ }^{5}$

As Lakoff and Johnson have so powerfully demonstrated, metaphors are not simply imaginative flourishes but are essential to the way humans think, describe reality and act, offering a "systematicity that allows us to comprehend one aspect of a concept in terms of another." 6 A metaphor is commonly based on our embodied condition, serving as "as a vehicle for understanding ... only by virtue of its experiential basis." 7 Thus with metaphor "we typically conceptualize the non physical in terms of the physical that is, we conceptualize the less clearly delineated in terms of the more clearly delineated." 8

Metaphors "as nomadic terms that link disparate discourses" not only draw connections between a condition we are seeking to explain and another, more familiar entity, they draw connections between the (problematic) condition and a world of associations corresponding to that new entity. ${ }^{9}$ As such metaphors expand possibilities for working through the condition we may be struggling to explain, offering new trajectories of conceptualization that unbind us from sedimented understandings. Despite access to this new world of potential insight, however, not all characteristics we associate with the source domain tend to transfer, rather only those that are resonant (however unexpectedly). Lakoff and Johnson describe the characteristics that do transfer as constituting a coherent network of entailments that highlight certain aspects of the problematical domain while obscuring others. The very 
power of a metaphor lies in this simultaneous illumination of certain meanings - again, often novel in conception - and concealment of others, a condition that is significant to architectural innovation as we shall see.

Nowhere is such meaningfully creative alteration more evident than in the introduction of new metaphors:

"If a new metaphor enters the conceptual system that we base our actions on, it will alter that conceptual system and the perceptions and actions that the system gives rise to. Much of cultural change arises from the introduction of new metaphorical concepts and the loss of old ones." 9

In preliminary phases of the architectural design process, the merit of a conceptual organizational idea is evaluated in terms of how it makes explicit those aspects of the project deemed critically important while at the same time accommodating - although not necessarily highlighting - a host of other concerns. As G.Z. Brown explains, "building design is a creative process based on iteration: one begins by responding to a situation with an abstract idea. Then one objectifies the idea, by proposing a trial design, evaluates it, redesigns it, develops it, reevaluates it, and so on." 10 Striving for coherence given a density of conditions and requirements - legal, practical, political, aesthetic, economic, topographic - is central to this undertaking. Because of their potential in inspiring insights that may help cohere and prioritize such conditions, new metaphors can function as effective tools in this process. A metaphor may suggest itself to a design team member in the conceptual design phase, revealing for all enriched discernment as to the specific nature of the problem and perhaps larger aspirations for what architecture can be. In subsequent design stages, additional metaphors may call attention to certain emergent traces of coordinated assemblage, of parts of the project or with the project as a whole, helping a team arrive at and share an appropriately interpretable vision that guides future action.

While Lakoff and Johnson contend, "most of our fundamental concepts are organized in terms of one or more spatialization metaphors," the architect working with metaphor performs an act of "respatialization." 11 Louis Kahn's famous dictum for the Phillips Exeter Library in New Hampshire, "taking a book and bringing it to the light" provides a wonderfully elaborated example of such a process. A conceptual notion (how we gain knowledge) originates in embodied experience (vision made possible by the presence of light, such that light enabling vision = knowledge). Kahn projects this construct back upon the physical realm through patterns of spatio-luminous organization "embodied" in the Library: one literally takes a book from a low-ceilinged and relatively dark "stack space" and brings it to a generously daylit study carrel at the building's periphery.

We might view Kahn's appropriation of this metaphor as a high modernist's deployment of an enlightenment notion of humankind's privileged access to the light of knowledge and what better building than a library for the encouragement of such a cerebral "reading." But a more favorable, experiential interpretation presents itself, that Kahn's respatialization enables profoundly rich, nuanced spatial engagement that does not stop or become isolated through the act of reading, where the process of finding a book and reading it is inseparable from - threaded with tactility, view, footfall, passage, etc.

Certain metaphors are transformative, arise unexpectedly, reverberate throughout design culture and change how architects see their work. In the contemporary world characterized by daily reminders of the degradation of our natural surroundings, such awareness of metaphors as productive agents of change would seem to encourage seeking notions that lead to greater environmental attunement. In the past other conditions prevailed and called for different insights. When for example Le Corbusier proclaimed, "the house is a machine for living in," he not only captured the exuberance felt toward the cool rationality of industrialization in the 1920's, but also directed a primary line of inquiry amongst architects for the remainder of the twentieth century. Through the use of the house-is-amachine-for-living-in metaphor, Le Corbusier both unapologetically acknowledged a reality - the architect's increasing involvement with industrial modes of production and the conceptualization of buildings as self-contained and also directed action towards the further fulfillment of such reality. Over time the notion was subjected to sociohistorical sedimentation, and the idea that a building is a machine continues to inhabit/inhibit design thinking today.

For a new metaphor such as this to have such influence, it must, like all metaphors "provide coherent structure, highlighting some things and hiding others" through a coherent set of entailments. ${ }^{12}$ The entailments that make Le 
Corbusier's metaphor the house is a machine for living in not only possible but powerful in transforming our thinking about the nature of the house and how one goes about designing a house include such notions as:

- A house is rationally organized

- We appreciate a house for its spare elegance and utility

- A house is the result of industrial manufacturing processes

- A house is made from machine-like materials

- A house is self-contained, "complete" (independent of its environment)

With Le Corbusier's cleanly ordered, taut-skinned early residential work, these machine-like qualities are highlighted, concretizing a more encompassing modernist project of the simultaneous theoretical dichotomization of culture and nature and the functional entanglement of what Bruno Latour terms "nature/culture" hybrids. For the moderns the house becomes conceptualized and expressed as an atemporal product, appearing to have been generated by a set of internalized operations, when in fact powerfully interwoven networks of "nature/cultures" systems of appropriation of resources in the service of human needs such as water supply and return, electrical power, air conditioning, materials assemblies, etc. - enable its very existence. As Latour suggests, it is the very denial of these proliferating nature-cultures that allow the modernist project to be so reserved and absolute:

"They are going to be able to make nature intervene at every point in the fabrication of their societies while they go right on attributing to nature its radical transcendence; they are going to be able to become the only actors in their own political destiny while they go right on making their society hold together by mobilizing nature." 13

For Latour, once we make explicit the proliferation of nature/culture hybrids concealed by a machine metaphor, accept the complicated linkages and admit our inability to comprehend them fully, we immediately become "nonmodern" and more sensitive in our interactions with our environment. As we will see, this entanglement of nature/cultures is made manifest in a new constellation of metaphors informing "green" architectural approaches.

"Constellation" ("braids" or interconnected strands of thought) speaks of the multiplicity of metaphorical notions in operation by contemporary environmentally concerned architects. Van der Rijn Architects seek to maximize those times when a building can "sail," that is, exist in "openmode" and allow prevailing breezes to provide cooling and ventilation, such as with the remodel of Draper Hall at Berea College in Kentucky. ${ }^{14}$ Client "sailors" are provided instructions on how to rig the ship (how to configure windows shades and other operable architectural features) during those times when the building is sailing. Similarly, the passive design expert John Reynolds promotes a "switch-rich" approach towards detailing, such that inhabitants are able to make countless adjustments to architectural elements comprising a building's façade in response to changing ambient conditions. The Australian architects Glenn Murcutt and Richard Leplastrier envision their roles as "designing encampments" and "furnishing outdoor rooms" - descriptions that encourage an architecture of resourceful elegance and "lightness" - while Michael Singer and Blackbird Architects view a work of architecture as not only in but as a landscape. With the IBN (Dutch) Institute for Nature Research in Wageningen, the German firm Behnisch \& Partner conceptualizes architecture as a complex organism. Such plurality of operative expressions in use today - and these are only a few - deserve comprehensive discussion. For the purposes of this paper, however, I will concentrate on two illustrative, transformative metaphorical notions and the attributes they share that inspire responsive practice.

\section{Organism As Bauplan For Architecture}

"Underneath the rhythm of every art and every work of art there lies, as a substratum in the depth of the subconscious, the basic pattern of the relations of the live creature to his environment." - John Dewey ${ }^{15}$

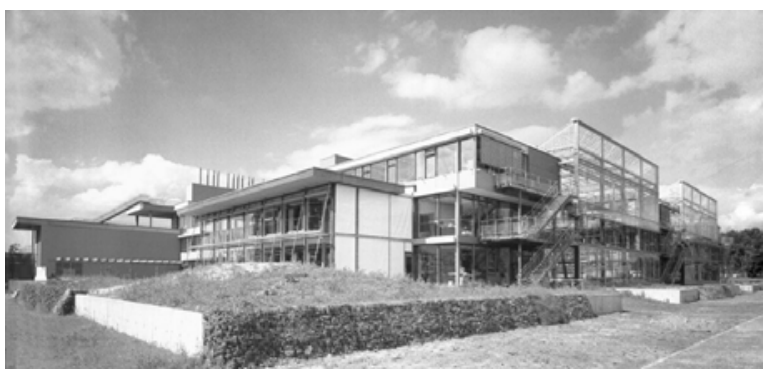

Figurel: IBN Nature Research Institute, Wageningen, The Netherlands (Behnisch \& Partner, 1996): exterior view of west and south facades 
In 1993, Stuttgart-based Behnisch \& Partner Architects won an invited competition for their design for the IBN (Dutch) Institute for Nature Research, a European Union pilot project for "human and environmentally-friendly building." 16 During the competition phase and throughout the life of the project, the design team elaborated in narrative and graphic form architectural qualities corresponding to those of a complex organism. One operative metaphorical notion among several, architecture as organism catalyzed design thinking with respect to the project in its entirety, to fine detail, and most critically how the whole and its parts were related to the IBN's milieu, a mixed agricultural and suburban context within the Rhine watershed in the eastern part of the Netherlands.

A formation of 60 ' x 100 ' "postage stamp" shaped gardens arranged axially serve as the project's primary organizational structure, with each garden representing a regional biotope; a grassland garden, a marsh garden, a woodland garden, etc. Each of three office wings is situated between two of the gardens and is said to "grow between the gardens." As an initial and formative gesture, the network of gardens provides stability for the building-asorganism to find "purchase," a niche of particular suitability. The IBN as Organism coheres within itself - it has internal organizational logic that is the residue of past articulations: the inclinations and previous experiences of the designer, the programmatic needs of the client, the technical rigors of building as embodied in the "code," etc. At the same time, as with an organism, the IBN "contains a reference to its future." 17 In the likely event that the Institute's scope and mission evolves, that it secures grants, hires researchers and finds itself in need of additional space, the garden structure and laboratory wing to the north anticipate the location of new offices. The adaptable portions of the building unfurl against a fixed armature. Merleau-Ponty's notion of organism as described by Mark Hansen is illuminating of both inhabitation and inhabitant initiated architectural response: "Behavior is what transforms such intrinsic potentiality into history while simultaneously preserving it as a "source" for future growth." 18 The IBN is incomplete, is never complete but "weak formed," ever adaptable to changing needs, to the disquiet of persistent animation within.

Singled glazed greenhouses - inexpensive and easily obtainable in The Netherlands - span gardens between office wings. The atria that are created serve as the offices' "lungs," providing warmth in winter and coolness in summer, enabling a dramatic downsizing of the heating system, and obviating the need for air conditioning altogether. Because the greenhouse roofs provide a first layer of protection against the elements, the office facades become light and "porous" centers of sensation, a skin that

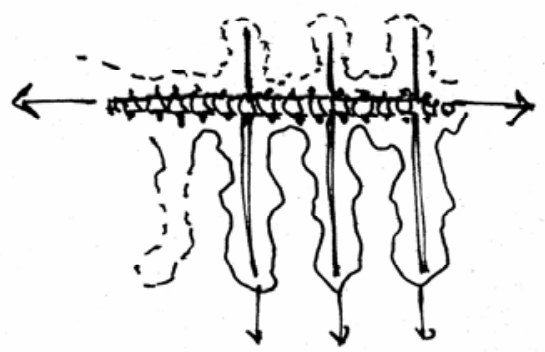

Figure 2: IBN Institute diagram "Organizational Spine/ Adaptable Limbs"

actively, selectively absorbs and transmits (the wanted) and refracts and transforms (the unwanted). With offices facing and open to gardens, the atria become the Institute's social heart, where scientists gather, conduct research and confer.

The IBN holds true to a contemporary understanding, as described by Robert Mugerauer, of both "the unity of the organism, and the dynamic, interactive relationship that organisms have with their environments." 19 A play exists between the IBN's intrinsic dispositions and those entities and phenomenon with which it is engaged in the "Umwelt" to which it adheres. Again Merleau-Ponty on the organism, "We have a section (intersection) that creates a new territory, and the place of the section decides what will be regenerated because it prescribes to the internal dynamic what it has to produce in order to retrieve its equilibrium." 20 There is a thematic open-endedness to the adjustment of vent openings and deployment of operable shades in the IBN's greenhouse roofs and porous facades and the drawing of cool air across the concrete mass (corpus) of office floors, a setting into action prescribed by the disequilibrium created by changes in surroundings - of shifts in temperature, light, and the movement of air.

In the descriptions of the design of the IBN above, we may be led to regard Behnisch \& Partner's metaphorical 
appropriations of an organism's attributes as a vehicle for aesthetization. Yet we may consider aesthetization favorably, not framed or isolated but implicated in all our actions and artifacts, and in agreement with Dewey's assertion that "esthetic effect is due to art's unique transcript of the energy of things of the world." 21 The very inseparability of appearance and behavior, expression and content distinguishes the IBN and has made it of one most acclaimed green projects in contemporary culture. As but one example, rainwater falling on the IBN greenhouse roofs is collected and diverted to reflecting pools in the atria gardens, where it is in used for irrigation. Evapotranspiration by the plants within the atria produces a cooling effect and along with natural ventilation become the building's "air conditioning." Bench-like platforms built into the sides of reflecting pools provide a contemplative setting for IBN staff to take work breaks. In this instance and throughout the project, ambiguity exists as to where aesthetic concerns trail off and where functional, ecological, spatial or thermodynamic conditions begin. Merleau-Ponty suggests that "animals acts are the manifestation of a certain style" and "instinct is before all else a theme, a style that meets up with that which evokes it in its milieu." 22 As with the animal, the IBN's patterning of functioning behavior, its disposition, is also a style, a manner of being, a measure of grace, inseparable from action.

\section{Furnishing Encampments}

"The less material place is, the more powerful it becomes." Edward Casey ${ }^{24}$

Students partaking in the 2001 Glenn Murcutt Master Class in Bundannon, New South Wales, Australia, were asked to design a gallery in a bowl-shapes meadow adjacent to Murcutt's Riversdale Educational Retreat Center (1999). In visiting the site on a crisp winter morning, architect and tutor Richard Leplastrier suggested that the primary task of the architect was that of "furnishing with particular purpose this larger room we are in." 25 This notion had an immediate effect on students' thinking, shifting concern from designing a building to a process more receptive of landscape and climate, to the creation of more diverse habitat. Leplastrier's metaphorical notion of a meadow having room-like qualities awaiting furnishings liberated the students to "pull apart" the building program, to examine critically whether hallways, restrooms, the café and storage needed the same level of climate control and environmental separation as the galleries. For many of the Gallery's spaces, minimal, furnishing-like provisioning of shade and shelter in Bundannon's benign Mediterranean-like climate was deemed acceptable. Conceiving the gallery not as an object in a field but rather an assemblage of activity settings in a spatial continuum including neighboring buildings and the tree-fringed meadow led to (otherwise unrealizable) opportunities for energy savings and material efficiencies and enriched thermal experience and visual engagement of the meadow room.

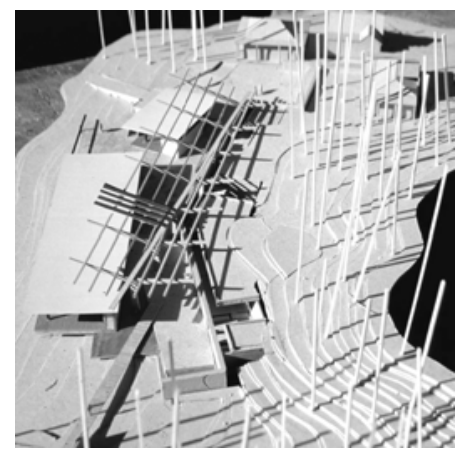

Figure 3: Model of gallery project for 2001 Glenn Murcutt Master Class (by author, I velisse Otero and Craig Tan)

Entailments associated with the compound metaphor architecture as furnishing a larger room might include notions such as:

- Our environment is comprised of spaces that have roomlike qualities

- Outdoor rooms have an ability to provide some measure of human comfort and protection

- Architecture can be made up of sets of furnishings

- One arranges sets of architectural elements in a room

- Architectural elements may be repositioned as per user needs and ambient conditions

- Architecture can be lightweight, perhaps portable

- Architecture should be functional, ergonomic and comfortable

With this notion we first infer that the environs of a building project have room-like qualities, and the furnishings we employ are participants in this context. Before designing, one of our first tasks should be to observe and identify the size, complexity, orientation, materiality, structure and quality of light of this room, as these qualities have a 
profound ability to condition - shelter, screen, brighten and envelop - the to-be-designed subspaces that will serve as the nexus of human activity.

A next critical operation is the assigning of characteristics to traditional architectural elements we more typically attribute to contemporary furnishings, qualities such as unpretentiousness, economy, lightness, and even portability. Furnishing-like building components such as window and bay assemblies, awnings and shade elements, partitions and screens can be configured and modified to allow sensitive, comfort-providing adjustment in an elegantly purposeful way. Thoughtfully located, flexible furnishing-like building elements serve as the interface between sheltered and preexisting space, encouraging greater responsiveness to the surrounding room versus a distancing of automation. While Kahn with the Exeter Library elevates the role of furnishings, integrating desks with windows such that they are primary to the building's identity, with Leplastrier "built" furnishings acquire preeminent status, and fixed walls and other immobile elements assume tertiary space defining functions.

Leplastrier's own pavilion-like one-room house in Lovett Bay, near Church Point and north of Sydney, "an adjustable house that can be attuned to climatic circumstances like a yacht adjusting to changes in the wind," might best exemplify his attempt to realize a furnishing-like architecture. ${ }^{26}$ The simple shed roofs, extending beyond wall planes to shade interior space during the hot summer months, are offset by platforms of varying levels that define distinct settings yet preserve spatial continuity. The slight elevation change - a step - that is the juncture of the main pavilion and the surrounding deck is at once a seat, a frame and a demarcation; a sectional jog that promises opportunities for repose and interaction, clarifies siting intentions and frames views of the Hawkesbury River and layers of "bush" cloaked hills beyond. As with a traditional Japanese house, vertical screens are minimal, light and flexible, providing a basic yet refined environmental control in the "friendly" climate of southeastern Australia.

In his work The Body in the Mind, Mark Johnson maintains that

"We almost always superimpose a container schemata on our center-periphery orientation. Where we draw the bounding container will almost always depend on our purposes, interests, perceptual capacities, conceptual system, and values. But we tend to define both our physical and mental identities by virtue of their containment." 27

"Bounding" may be preferred over containment in describing ourselves and our surroundings, a boundary being richly capable of expression and orientation, as much a threshold of interaction as division. And so we may adjust Johnson's assertion and posit that as embodied creatures we simultaneously conceive ourselves as exhibiting boundedness and perceive bounding entities in our surroundings. And it is possible for us to adjust our understanding of the breadth of this encircling, such as with the notion of architecture as furnishing this larger room, where a built entity is less a primary boundary and more a (porous) mediator between our selves and larger entities, rooms that are at once tremendously spatially complex and comforting in their bounding comprehensibility. The metaphor, and the work of Leplastrier informed by such an articulation, encourages radical reappraisal of our situatedness: our architectural furnishings, surfaces as bodily extensions and settings for gathering, are "outfoldings" towards our primary inhabitation, an environment, a horizon, a landscape under the stars. We simultaneously experience intimacy and close familiarity and a "flux of awareness" of the bounding everchangingness of our surroundings. A fluid, mobile connectedness is intimated as a basic way in which humans engage with the world, (re)calling to mind Murcutt's notion of architecture as "encampment" and inviting Karsten Harries' claim that "we cannot really be at home in the world as long as we fail to accept that we are wayfarers, nowhere fully at home." 28

\section{Design as Hinge, as Act}

If we agree with Van der Ryn that "design is a hinge that inevitably connects culture and nature through exchanges of materials, flows of energy and choices of land use," then conceptualizations of architecture described above might help to encourage disclosure of and graceful engagement with exchanges previously obscured, when for example sun and wind and light come into contact with the elements that comprise works of architecture.$^{29}$ Architecture becomes envisioned as resourcefully abundant assemblages of networks and flows that concentrate at the loci of human activity. Not only are spatial and formal conditions acknowledged but other, dynamic qualities as 
well, as Harrison Fraker suggests with regard to passive climate control strategies:

"A complete understanding of the relevance of passive concepts on architectural form goes beyond the formal analysis of visual qualities alone. It requires perception ... of thermal and luminous phenomenon that are not visible in the same sense as architectural space. Boundaries in the thermal or luminous environment are subtle and not sharply defined." 30

Whereas architecture as building emphasizes an iconic image - the singularity and static fixity of a work, architecture as organism and architecture as furnishing a larger room, in suggesting the desirability of formal weakening, and by demanding recognition of something beyond the work itself, suggest critically that the task of the architect is an intertwining of making and world that conditions intertwining of (human) organisms and environment. Architecture becomes dynamic, responsive and activated, an understanding that resonates with Ricoeur's very notion of metaphor; "to present all things 'as in act' - such could well be the ontological function of metaphorical discourse, in which every dormant potentiality of existence appears as blossoming forth, every latent capacity for action as actualized." 31

As I have attempted to argue in this essay, (1) by employing metaphors in the design process architects frame an awareness of certain conditions that influence the direction of future explorations, and (2) "green" metaphors invite greater environmental attunement and therefore are helping reshape practice for the better. The question arises, therefore, as to how such recognition of the influence of metaphors on greenness of outcomes might have a positive bearing in future undertakings (?). Might we encourage a straightforward appropriation of metaphors identified in this paper as one embarks on a new building project? Might we stretch the implications of these, extending their entailments further, or combine them with others? Or should new metaphorical expressions emerge out of the contextual and programmatic circumstances unique to a particular project? While I offer no definitive answer, I suggest the latter possibility as highly promising, that effective alignments between conceptual organizational strategies and project conditions will result from unselfconscious metaphorical meditations that emerge from and not in advance of the

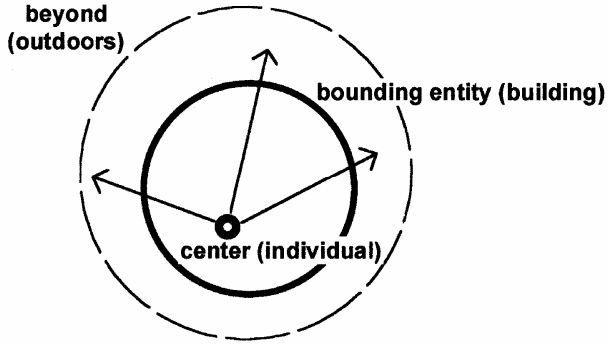

Figure 4: "Traditional" center-periphery orientation

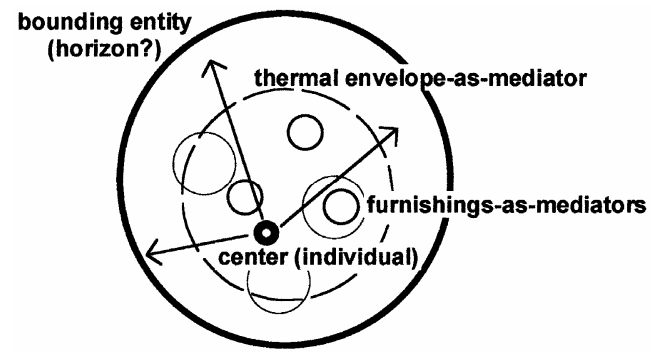

Figure 5: Extension of bounding entity via notion of "architecture-as-furnishings"

process itself. The development of IBN as organism supports this thesis - that we seek realizations and not impositions.

However we proceed, in recognizing design as a hinge, we may be encouraged to seek allegiances with and understand the languages of those who are articulate and innovative with respect to environmental understandings and initiatives. For the author for example, the architectural design studio becomes a venue for research, and a pilot "simultaneous infill housing/oak habitat restoration" studio collaboration has recently been conducted involving a professional restoration ecologist. By exposing architecture students to the language of restoration ecology from day one, students are inspired to consider the conceptual, metaphorical and morphological implications of such notions as "peninsular interdigitation," patch/matrix "breaks," "edge/corridor effects," and "core reserves." 32 Results from this experiment suggest that new understandings of architecture can emerge from such a process, that "ecotones" or methodological and spatial overlap zones can be generated as a result of unorthodox descriptions of the problem of design. By summoning more 
encompassing portrayals of our operations and impacts, descriptions that address ecological integrity and health in our cities, designers are better able to realize projects that minimize disruption and even engage in beneficial, symbiotic relationships with surrounding ecosystems.

\section{Conclusion}

"Just as texts are built, so buildings are written." - Edward Casey ${ }^{3}$

While care must be taken not to give primacy to any single component in the complex enterprise of architectural design, it should also not be overlooked that our most widely shared descriptions of what architecture is - a foundation of culture, a "castle," a "machine for living in," and very likely the idea of a building itself - are contingent and have been promulgated via metaphorical insight. If a primary purpose of metaphor is "to bring to light new resemblances the previous classification kept us from seeing," given the incongruity that many sense exists between built entities - that are fixed, static and sluggish and our understanding of the world - as active, dynamic, simultaneously disclosing and concealing, the very incongruity of the metaphors we have discussed might prove fruitful in animating our discourse and in evolving our thinking as to what architecture can be. ${ }^{34}$ Language intervenes and activates, strict interior conditions and controls loosen, (minor) fluctuations become tolerable even desirable, and dynamic, expressive opportunities emerge. Forms relax (weaken), interactions intensify, clients sail. Architectural innovation is instantiated through inventive, concerned description of the kind of world active, inclusive, diverse, fragile - we see value in making.

\section{Endnotes:}

\footnotetext{
${ }^{1}$ David Abram, The Spell of the Sensuous (New York: Vintage, 1996), 84

${ }^{2}$ Edward S. Casey, Getting Back Into Place: Toward a New Understanding of the Place World (Bloomington, IN:

University of Indiana Press, 1993), p. 259.

${ }^{3}$ Simon Guy and Steven A. Moore, "Introduction: The Paradoxes of Sustainable Architecture," in Simon Guy and Steven A. Moore, eds., Sustainable Architectures: Cultures and Natures in Europe and North America (New York: Spon Press, 2005), p. 2.

${ }^{4}$ My observations as to the impact of metaphorical insight in the architectural design process owes much to the work of George Lakoff and Mark Johnson, in particular their book
}

Metaphors We Live By in which they offer a systematic framework for clarifying the pervasive influence of metaphors in our thinking.

${ }^{5}$ George Lakoff and Mark Johnson, Metaphors We Live By (Chicago: University of Chicago Press, 1980), 158.

${ }^{6}$ Lakoff and Johnson, Metaphors We Live By, 10.

${ }^{7}$ Lakoff and Johnson, Metaphors We Live By, 18.

${ }^{8}$ Lakoff and Johnson, Metaphors We Live By, 59.

${ }^{9}$ James D. Proctor and Brendon M. H. Larson, "Ecology,

Complexity, and Metaphor," in Bioscience Volume 55, No.12 (December, 2005), p. 1066

${ }^{10}$ G.Z. Brown, "Desirable Interface Characteristics of Knowledge-Based Energy Software Used by Architects," American Society of Heating, Cooling and Air Conditioning Engineers Annual Meeting, Saint Louis, 1990, 1-2.

${ }^{11}$ Lakoff and Johnson, Metaphors We Live By, 17.

${ }^{12}$ Lakoff and Johnson, Metaphors We Live By, 139.

${ }^{13}$ Bruno Latour, We Have Never Been Modern, transl. Catherine Porter (Cambridge, MA: Harvard University Press, 1993), 32.

${ }^{14}$ I wish to thank to Rob Pena, project architect on the Draper Hall project, for furnishing documentation on this and other works by Van der Rijn Architects.

${ }^{15}$ John Dewey, Art as Experience (New York: Perigee Books, 1980, originally published 1934), 150.

${ }^{16}$ Please see my paper "Archipelagoes of Weak Formed Buildings: Contemporary Ecology Informing Contemporary Architecture," American Collegiate Schools of Architecture Annual Conference, Miami, FL, 2004 for a more thorough consideration of the IBN. The description is a firsthand account as I worked for Behnisch \& Partner from 1993-1997 and was a lead member of the IBN design team from the competition phase through construction.

${ }^{17}$ Mark B.N. Hansen. "The Embryology of the (In)visible," in The Cambridge Companion to Merleau-Ponty (Cambridge, UK: Cambridge University Press. 2005), 239.

${ }^{18}$ Hansen, "The Embryology of the (In)visible," in The Cambridge Companion to Merleau-Ponty, 239.

${ }^{19}$ Robert Mugerauer. "Deleuze and Guattari's Return to Science as a Basis for Environmental Philosophy," in Rethinking Nature: Essays in Environmental Philosophy (Bloomington, IN: Indiana University Press, 2004), 193.

${ }^{20}$ Maurice Merleau-Ponty, Nature: Course Notes from the College de France, trans. Robert Vallier (Evanston, IL: Northwestern University Press, 2003), 234.

${ }^{21}$ Dewey, Art as Experience, p. 185.

${ }^{22}$ Merleau-Ponty, Nature: Course Notes from the College de France, 192.

${ }^{23}$ Merleau-Ponty, Nature: Course Notes from the College de France, 193.

${ }^{24}$ Edward S. Casey, The Fate of Place: A Philosophical History (Berkeley, CA: University of California Press, 1997), 90.

${ }^{25}$ For a more comprehensive consideration of the work of Leplastrier and the context of this quote, please see my paper "Lightness of Building: Furnishing a Regenerative Architecture," American Collegiate Schools of Architecture Annual Conference, Louisville, KY, 2003.

${ }^{26}$ Rory Spence, "Heightened Senses," The Architectural Review April (1998), 70. 


\footnotetext{
${ }^{27}$ Mark Johnson, The Body in the Mind: The Bodily Basis of Meaning, Imagination and Reason (Chicago: University of Chicago Press, 1987), 125.

${ }^{28}$ Karsten Harries, The Ethical Function of Architecture (Cambridge, MA: MIT Press, 1997), 166.

${ }^{29}$ Sim Van der Ryn and Stuart Cowan, Ecological Design (Washington, D.C.: Island Press, 1996), 8.

${ }^{30}$ Harrison Fraker, "Formal Speculations on Thermal Diagrams," Progressive Architecture, April (1984), 104.

${ }^{31}$ Paul Ricoeur, The Rule of Metaphor: Multi-Disciplinary Studies of the Creation of Meaning in Language, trans. Robert Czerny (Toronto: University of Toronto Press, 1977), 40.

${ }^{32}$ See Richard T.T. Forman \& Michel Godron, Landscape Ecology (New York: John Wiley \& Sons, 1986) and Forman's

Land Mosaics: The Ecology of Landscapes and Regions (Cambridge, UK: Cambridge University Press, 1995)

${ }^{33}$ Casey, The Fate of Place: A Philosophical History, 310.

${ }^{34}$ Paul Ricoeur, The Rule of Metaphor: Multi-Disciplinary Studies of the Creation of Meaning in Language, 197.
} 